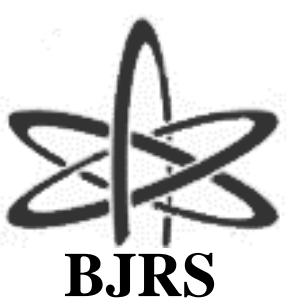

BRAZILIAN JOURNAL

$\mathrm{OF}$

RADIATION SCIENCES

03-02 (2015) 01-04

\title{
Dosimetria Retrospectiva de Unha por Ressonância Paramagnética Eletrônica
}

\author{
Ricardo A Giannoni ${ }^{1}$, Orlando Rodrigues $\mathrm{Jr}^{2}{ }^{2}$ \\ ${ }^{1}$ Instituto de Radioproteção e Dosimetria (IRD) \\ Comissão Nacional de Energia Nuclear (CNEN) \\ Av Salvador Allende, $\mathrm{s} / \mathrm{n}$ \\ 22783-127 Rio de Janeiro - RJ- Brasil \\ giannoni@ird.gov.br \\ ${ }^{2}$ Instituto de Pesquisas Energéticas e Nucleares (IPEN) \\ Comissão Nacional de Energia Nuclear (CNEN) \\ Av. Professor Lineu Prestes, 2242 \\ 05508-900 São Paulo - SP - Brasil \\ rodrijr@ipen.br
}

\begin{abstract}
A proposta deste trabalho é de caracterizar amostras de unhas humanas, submetidas à irradiação de altas doses, através da técnica de Ressonância Paramagnética Eletrônica (RPE). O objetivo é estabelecer uma relação dose/resposta que permita avaliar níveis de dose absorvida por indivíduos expostos em situações de acidentes radiológicos, de forma retrospectiva. Amostras de unhas humanas foram irradiadas com radiação gama, e receberam dose de $20 \mathrm{~Gy}$. As medidas de RPE realizadas nas amostras, antes da irradiação, identificaram sinais de RPE associados a defeitos causados pela ação mecânica da coleta da amostra. Após a irradiação outras espécies de radicais livres, associados à ação da radiação gama, foram identificadas.
\end{abstract}

Keywords:

Palavras-chave: Dosimetria, Ressonância Paramagnética, unha

\section{INTRODUCTION}

As substâncias que apresentam paramagnetismo são aquelas que contém 
elétrons cujos momentos magnéticos não estão cancelados, isto é, os átomos, íons, ou moléculas contém um número ímpar de elétrons, portanto, estão desemparelhados.

A técnica de Ressonância Paramagnética Eletrônica (RPE) detecta elétrons desemparelhados. Em geral em materiais sujeitos à irradiação aparecem defeitos na forma de radicais livres propícios a detecção por RPE. A intensidade do sinal de RPE, é proporcional à dose absorvida.

Os materiais inorgânicos mais utilizados são o MgO: $\mathrm{Mn}^{2+}$, estalactites, estalagmites, corais, conchas, hidroxiapatita, minerais, quartzo e rubi. Os orgânicos são os aminoácidos e os açucares. A natureza não destrutiva da detecção de RPE permite o estudo de espécies armadilhadas em amostras biológicas, tais como ossos, dentes e cabelos.

O propósito da dosimetria em situações de acidente crítico é avaliar rapidamente os níveis de dose absorvida pelos indivíduos expostos e permitir um rápido diagnóstico, além de elaborar métodos que serão empregados para determinação exata das contribuições dos diferentes tipos de radiação à dose absorvida. A reconstrução da dose pode ser necessária em uma variedade de situações.

A dosimetria por RPE tem sido pouco utilizada na análise retrospectiva de acidentes radioativos pela dificuldade de se obter amostras de dentes ou tecido ósseo. A obtenção desse tipo de amostra depende de procedimentos invasivos, além da posterior separação da matéria orgânica da estrutura da hidroxiapatita, seja do osso ou do dente.

A proposta deste trabalho é de caracterizar amostras de unhas humanas submetidas à irradiação de altas doses através da técnica de RPE para estabelecer uma relação dose/resposta que permita avaliar níveis de dose absorvida por indivíduos expostos em situações de acidentes radiológicos, de forma retrospectiva.

Em todo texto, use os tamanhos e formatos deste modelo. Para citar as referências, utilize o Estilo ABNT. 


\section{MATERIAIS E MÉTODOS}

Amostras de unhas humanas, coletadas dos autores deste trabalho, foram irradiadas com radiação gama, e receberam dose de 20 Gy. Essas amostras foram medidas, antes e depois da irradiação, por espectroscopia de Ressonância Paramagnética Eletrônica (RPE) de onda continua (CW), em banda - X ( 9,7 GHz), utilizando modulação de $100 \mathrm{kHz}$, na temperatura ambiente, em espectrômetro BRUKER modelo EMX.

\section{RESULTADOS E DISCUSSÕES}

As medidas de RPE realizadas nas amostras antes da irradiação, identificaram radicais livres associados a defeitos causados pela ação mecânica na estrutura da unha, devido a ação do corte mecânico para a retirada da amostra. Esse sinal é denominado de sinal mecanicamente induzido (SMI). A estrutura do sinal SMI é complexa. Inicialmente identificamos nesse espectro uma componente principal em aproximadamente $\mathrm{g}=2,004$.

O sinal de RPE na amostra irradiada é devido a ação da radiação ionizante na estrutura da proteína fibrosa denominada de queratina que compõe a unha. Essa interação gera sinais detectáveis por RPE, e denominamos esses sinais de sinais induzidos por radiação (SIR). Esse sinal SIR pode estar superposto ao sinal do SMI. Por esse motivo é necessário a caracterização de amostras antes e após irradiação, para obter conhecimento da intensidade, dependência temporal, e outros fatores como, por exemplo, umidade que podem modificar as espécies geradas pelas interações nos sinais SMI e SIR.

Pode-se eliminar o sinal SMI, ou minimizá-lo, antes de irradiar a amostra tratando-a com água, de forma adequada.

O espectro medido após irradiação mostra uma componente principal em aproximadamente g = 2,003 .

Conforme a literatura ${ }^{2}$, no intervalo entre 1 e 125 Gy a relação dose-resposta é linear. Optamos irradiar as amostras com a intensidade de 20 Gy como um teste inicial e obtivemos resultados positivos. 


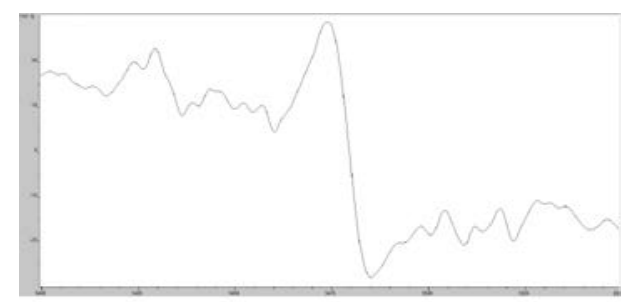

Figure 1. Sinal de RPE de radical causado pela ação mecânica do corte da unha.

\section{CONCLUSÕES}

Em amostras de unhas irradiadas, em condições ótimas é possível detectar um sinal de RPE a partir de 1 Gy. Nosso atual estágio de conhecimento e de implementação da técnica requerem mais experimentos para atingir um estágio de validação, com a obtenção de uma curva doseresposta que permita sua utilização em situações reais e sugira níveis mínimos de detecção. $\mathrm{O}$ trabalho segue em andamento para atingir esses objetivos.

\section{REFERÊNCIAS}

1 - ISO/ASTM 51607:2004(E) - American National Standard. (www.astm.org)

2 - Electron paramagnetic resonance radiation dosimetry in fingernails. Radiation Measurements, 44, (2009) 6-10

3- Protocol for emergency EPR dosimetry in fingernails. Radiation Measurements, 42, (2007) 1085 - 1088 